\title{
Typology and Etiology of Precocious Puberty in Sub-Saharan Africa: Report of 8 Cases in Abidjan, Ivory Coast
}

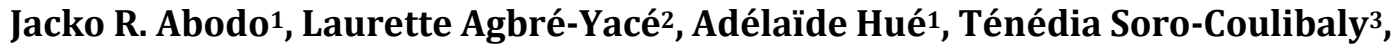 \\ Micondo Kouamé ${ }^{4}$, Mamadou Sanogo ${ }^{1}$, Jocelyne Danho' ${ }^{1}$, Jean B. Ahoussi ${ }^{1}$, Adrien Lokrou ${ }^{1}$ \\ ${ }^{1}$ Department of Endocrinology-Diabetology, University Hospital Yopougon, Abidjan, Côte d'Ivoire \\ ${ }^{2}$ Pediatric Endocrinology Unit, National Institute of Public Health, Abidjan, Côte d'Ivoire \\ ${ }^{3}$ Department of Pediatrics, General Hospital of Abobo Nord, Abidjan, Côte d'Ivoire \\ ${ }^{4}$ Pediatric Service, Military Hospital of Abidjan, Abidjan, Côte d'Ivoire \\ Email: sfadabidjan@yahoo.fr
}

How to cite this paper: Abodo, J.R., Agbré-Yacé, L., Hué, A., Soro-Coulibaly, T., Kouamé, M., Sanogo, M., Danho, J., Ahoussi, J.B. and Lokrou, A. (2017) Typology and Etiology of Precocious Puberty in Sub-Saharan Africa: Report of 8 Cases in Abidjan, Ivory Coast. Advances in Sexual Medicine, 7, 161-166.

https://doi.org/10.4236/asm.2017.74013

Received: June 29, 2017

Accepted: September 25, 2017

Published: September 28, 2017

Copyright $(0) 2017$ by authors and Scientific Research Publishing Inc. This work is licensed under the Creative Commons Attribution International License (CC BY 4.0).

http://creativecommons.org/licenses/by/4.0/

\begin{abstract}
Introduction: Early puberty is defined by development of secondary sexual characteristics before the age of 8 years in girls and 9 years in boys. In the West, one in five children out of 100,000 is concerned. Little information on sub-Saharan African patients exists concerning this pathology. Objective: To determine the etiology and clinical characteristics of early puberty in a cohort of Ivorian children. Methods: We conducted a cross-sectional study between 2015 and 2017 in children admitted to early puberty in the unique Endocrinology Service of the country. The epidemiology and clinical characteristics were assessed. Results: The eight patients involved were all females. Their mean age at diagnosis was 7 years and 3 months and the mean age of first symptoms begun at 5 years and 6 months. Seven patients had a central precocious puberty (CPP) including five cases of idiopathic CPP (ICPP) treated by (GnRH agonist) and two cases with secondary precocious puberty (SPP). One of them has a hypothalamic hamartoma and the other a sequelae of encephalopathy. The last case had a peripheral precocious puberty (PPP) causes by ovarian dystrophy. Conclusion: Our results confirm the predominance of idiopathic central precocious puberty particularly in girls.
\end{abstract}

\section{Keywords}

Early Puberty, Secondary Sexual Characteristics, Stature 


\section{Introduction}

Early puberty or precocious puberty (PP) is not uncommon. It is defined by the development of secondary sexual characteristics before age 8 in girls and before age 9 in boys. In the West, one to five children out of 100,000 are concerned predominantly female [1]. The etiological features of early puberty are numerous. Early central puberty occurs more often in girls than in boys. They are more frequent among adopted girls from developing countries [2]. In girls, they are more frequently idiopathic ( $80 \%$ of cases), whereas neurogenic causes are more common in boys (60\%). We must distinguish central early puberty involving pulsatile Gonadotropin-Releasing hormone $(\mathrm{GnRH})$ secretion due to premature activation of the hypothalamic-pituitary axis, early peripheral puberty due to secretion of sexual steroids by the gonads or adrenals. The central origin of early puberty is demonstrated by elevated basal pituitary gonadotrophins and/or stimulation by Luteinizing Hormone Releasing Hormone (LHRH). It is the response to the LHRH test which is the key to the diagnosis of central early puberty: LH peak greater than 5 IU/L. LH/FSH peak ratio > 0.66 [3]. Little work has been done on the issue in sub-Saharan Africa. However some show association with sexual infections [4].

\section{Objective}

Examine the etiology and clinical characteristics of early puberty in a cohort of Ivorian children.

\section{Methods}

We conducted a cross-sectional study between 2015 and 2017 from all cases of children admitted to early puberty in the unique Endocrinology Service of Ivory Coast. Patients in whom the diagnosis of PP was suspected or posed by the pediatrician or general practitioner were referred to us for management.

The data on sex, age, height, weight, body mass index, health history have been collected. The diagnosis of PP is based on evaluation of secondary sexual characteristics according to Tanner stage [5], the acceleration of the growth rate, the advance of bone maturation according to the Atlas of Greulich and Pyle [6], and the pituitary-gonadal biological activation, including levels of LH and FSH, estradiol. Pelvic ultrasound and computed tomography (CT) or magnetic resonance imaging (MRI) of the brain were made to find specific etiology. No attemps were done to identify any gene mutations like KISS1, MSRN3 because of non availability. Neurosurgery has been performed to treat harmatoma and gonadotrophin releasing hormone agonist used to slow down pubery and improve the adult weigh as possible although is cost remained prohibitive in our country.

\section{Results}

Eight patients had been identified and were all females with age at consultation varies from 7 years 3 months ( 2 years 9 months to 11 years) and age of onset of 
Table 1. Main characteristics of patients with early puberty.

\begin{tabular}{|c|c|c|c|c|c|c|c|c|}
\hline & 1 & 2 & 3 & 4 & 5 & 6 & 7 & 8 \\
\hline Age (years) & 2 ys 9 months & $6 \mathrm{ys}$ & $7 \mathrm{ys}$ & 7 ys 6 months & 7 ys 11 months & $8 \mathrm{ys}$ & $11 \mathrm{ys}$ & 7 ys 8 months \\
\hline Beginning of signs (years) & 2 & 5 & 6 & 5 & 6 & 7 & 6 & 6 \\
\hline \multicolumn{9}{|l|}{ Physical examination } \\
\hline SP & $\mathrm{S} 2 \mathrm{P} 2$ & S3P3, menarche & S4P4 & S4P4 Figure $1(a)$, Figure $1(b)$ & S4P3, menarche & S3P3 & S3P2 & S3P3 \\
\hline Weight $(\mathrm{kg})$; Height $(\mathrm{m})$ & $9.8 ; 0.86$ & $28 ; 1.30$ & $31 ; 1.24$ & $36 ; 1.37$ & $37 ; 1.39$ & $34 ; 1.37$ & $75 ; 1.56$ & $43 ; 1.4$ \\
\hline \multicolumn{8}{|l|}{$<95 ;$ Obesity $\geq 95$} & Overweight \\
\hline \multicolumn{9}{|l|}{ Biology } \\
\hline $\mathrm{FSH}(\mathrm{UI} / \mathrm{L})$ & 3 & 0.06 & 5 & 4.8 & 5.2 & 3.2 & - & - \\
\hline LH(IU/L) & 2.5 & 0.01 & 4 & 12 & 3.5 & 2.7 & & \\
\hline $\mathrm{E} 2(\mathrm{pg} / \mathrm{ml})$ & 0.1 & 46 & 0.3 & 1 & 4 & 5 & - & - \\
\hline \multicolumn{9}{|l|}{ Imaging } \\
\hline Bone age (years) & 5 & 7 & 10 & 11 Figure $1(c)$ & 11 & $121 / 2$ & 13 & 11 \\
\hline Pelvic Ultrasonography/ & - & Left ovarian cyst & - & - & - & - & - & - \\
\hline MRI/CT Scan & $\begin{array}{l}\text { Microcephalia by } \\
\text { Encephalitis }\end{array}$ & - & - & - & Hamartoma & - & - & - \\
\hline Etiology & SCPP & PPP & ICPP & ICPP & SCPP & ICPP & ICPP & ICPP \\
\hline Treatment & - & Decapeptyl & Decapeptyl & Decapeptyl & Neurosurgery & Decapeptyl & Decapeptyl & Decapeptyl \\
\hline
\end{tabular}

SP: Tanner classification, BMI: Body Mass Index, FSH: Follicle Stimulating Hormone, LH: Luteinizing Hormone, E2: oestradiol, MRI: Magnetic resonance imaging.

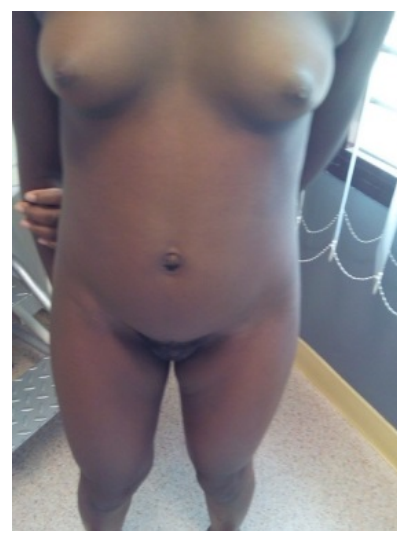

(a)

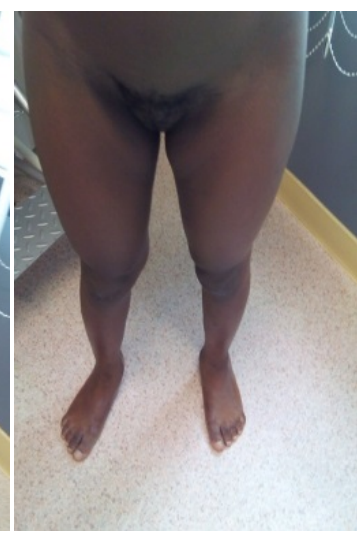

(b)

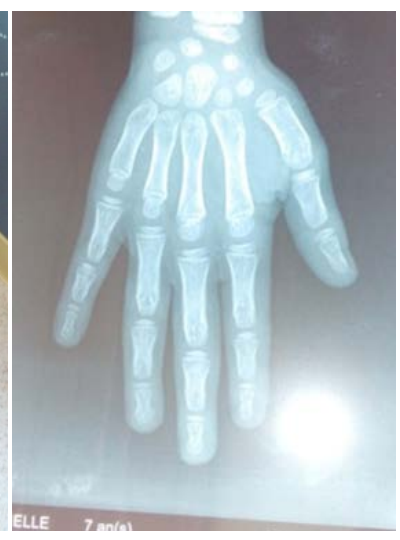

(c)

Figure 1. Child KS 7 years 6 months; P4 S4 (Tanner) and bone age to 12 and a half years. (a) Tanner S4; (b) Tanner P4; (c) bone age to 12 years.

signs 5 years 6 months ( 1 to 7 years). Clinical and laboratory examinations of our patients were classified into two categories, central PP (7 cases) and peripheral PP (1 case). Among the 7 cases of central PP 5 in which brain imaging and ultrasound were normal adrenals and ovaries did not show any abnormality were classified idiopathic (ICPC). Among the other 2 SPPC one had sequelae of encephalitis with microcephaly and the other hypothalamic hamartoma. Only one of the girls was diagnosed as peripheral PP (PPP) related to a left ovarian cyst. The 6 cases of ICPP were treated with GnRH agonist, the patient with a hamartoma had been surgically treat while microcephaly had no treatment due to lack of financial means. The main characteristics of the patients are listed in Table 1. 


\section{Discussion}

Precocious puberty is more frequent in girls [7]. All our patients were females and the youngest was under 3 years of age. The youngest child with early puberty reported in the literature was 6 months old [8].

In etiological aspects, PP has a multitude causes (Table 2) [9]. CPP is dominant and is most often idiopathic related to genetic factors (family), epigenetic (migration) or environmental (nutritional, endocrine disorders) [9]. The ICPP concerns $6 / 8$ of our cohort. Estimates of the frequency of central nervous system pathology causing CPP vary widely. In girls, estimation of idiopathic CPP range from $69 \%$ to $98 \%$, compared with $0 \%$ to $60 \%$ in boys.

In family ICPP there is central obesity as reported by Chen in China especially in women (38.9\%) [10]. Hypothalamic hamartoma is an uncommon cause of central precocious but has a significant importance [11] [12] and is often revealed by an epileptic seizure; we found one case with gelastic epilepsy and delayed psychological development. She presents vaginal bleeding during hospitalization in neurosurgery. Other neurological causes may be involved [9] including encephalitis leading to microcephaly in our patient. The cause of PPP is cyst or ovarian tumor, adrenal tumor, congenital adrenal hyperplasia, and Mc CuneAlbright syndrome. Our PPP patient with an ovarian cyst had elevated estradiol and decreased $\mathrm{LH}$ and $\mathrm{FSH}$.

In addition to the development of secondary sexual characteristics, puberty is associated with a rapid growth rate and bone maturation leading to a decrease of global final height [9]. This disorder may cause psycho-sociological problems especially in girls [13]. In Africa, particularly in the Republic of Congo, early puberty is perceived among girls as a risk of early sexuality, with corollary early marriage and pregnancy. To combat a PP in girls, family use several practices.

Table 2. Etiology of early puberty.

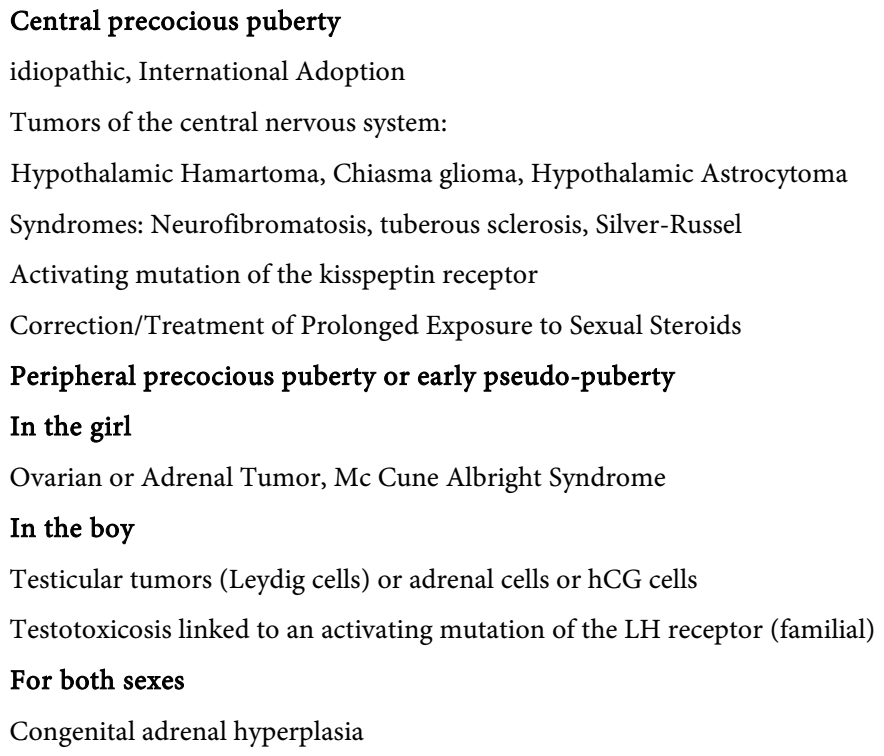


For mammary gland, it is often recommended regular palpation by a male subject of the family up to "disappearance" or compression by bandages. When it is more developed, the girl is inflicted with blows of a spatula, which may be moderate strength to extreme violence. For the hair hot water baths regularly is used [14]. However, when diagnosed and treated earlier is started properly progresses to slowing puberty improving final height in patients [15].

\section{Conclusion}

The authors advocate the sensitization of the populations in order to make early diagnosis and treatment. However MRI is inaccessible and gonadotrophin releasing hormone which is indicated to slow puberty and improve final height has excessive cost.

\section{References}

[1] Bouvatier, C. (2014) Early Puberty. Springer-Verlag.

[2] Baron, S., Battin, J., David, A. and Limal, J.M. (2000) Precocious Puberty in Children Adopted from Foreign Countries. Pediatric Archives, 7, 809-816.

[3] Fuqua, J.S. (2013) Treatment and Outcomes of Precocious Puberty: An Update. The Journal of Clinical Endocrinology \& Metabolism, 98, 2198-2207. https://doi.org/10.1210/jc.2013-1024

[4] Glynn, J., Kayuni, N., Gondwe, L., Price, A. and Crampin, A. (2014) Earlier Menarche Is Associated with a Hygher Prevalence of Herpes Simplex Type-2 (HSV-2) in Young Women in Rural Malawi. eLife, 3, e01604. https://doi.org/10.7554/eLife.01604

[5] Marshall, W.A. and Tanner, J.M. (1969) Variations in pa TTERN of Pubertal Girls in Exchange. Archives of Disease in Childhood, 44, 291-303. https://doi.org/10.1136/adc.44.235.291

[6] Greulich, M.M. and Pyle, S.I. (1959) Radiographic Atlas of Skeletal Development of the Hand and Wrist. 2nd Edition, University Press, Stanford.

[7] Tfifha, I.M., Dhahri, D., Ajmi, H., Mabrouk, S., Kadri, K., Chemli, J., Zouari, N., Hassayoun, S., Tlili, K. and Abroug, S. (2014) Different Appearance of Precocious Puberty: Clinical Outcome and Experiance (8 Squares). Archives of Disease in Childhood, 99, A278.

[8] Nienaber, C.S. and Van Der Walt, D. (1991) True Idiopathic Precocious Puberty Presenting at Six Months of Age; a Case Report. European Journal of Obstetrics \& Gynecology and Reproductive Biology, 38, 243-245. https://doi.org/10.1016/0028-2243(91)90300-A

[9] Beauloye, V. (2016) Early Puberty. Louvain Medical, 4, 279-282.

[10] Chen, C., Zhang, Y., Sun, W., et al. (2017) Investigating the Relationship between Precocious Puberty and Obesity: A Cross-Sectional Study in Shanghai, China. BMJ Open, 7, e014004. https://doi.org/10.1136/bmjopen-2016-014004

[11] Ayadi, K.K., Ehdi, M., Khannous, M.M., et al. (1996) Hypothalamic Hamartomas: about Seven Observations. Tunisia Medical, 74, 135-137.

[12] Mbassi Awa, H.D., Abena Obama, M.T., Pondy, A., Pienkowski, C., Nko'o Amvene, S. and Mbede, J. (2011) Central Precocious Puberty Due to Hypothalamic Hamartoma in Cameroon. Med Trop (Mars), 71, 309-311. 
[13] Purper-Ouakil, D. and Didillon, A. (2016) Psychopathology Associated with Female Precocious Puberty. Encephale, 42, 453-457.

[14] Okoumou-Moko, A., El Mghari, G. and Ansari, N. (2014) Precocious puberty and ancestral practices in Republic of Congo. Annals of Endocrinology, 75, 409. https://doi.org/10.1016/j.ando.2014.07.466

[15] Hachicha, M., Kammoun, Th., Loulou, F., Guirat, N., Mahfoudh, A., Jardak, N. and Triki, A. (2002) Les puberties précoces centrales: Etude de 9 observations. [Central Early Puberty: Study of 9 Cases]. Revue Maghrébine de Pédiatrie, 12, 75-85. 